\title{
Making post-glacial uplift visible: A model based high- resolution animation of shore displacement
}

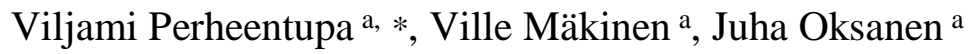 \\ ${ }^{a}$ Finnish Geospatial Research Institute FGI, National Land Survey of Finland, viljami.perheentupa@nls.fi, ville.p.makinen@nls.fi, \\ juha.oksanen@nls.fi \\ * Corresponding author
}

Keywords: Animated maps, Land uplift, Glacial isostatic adjustment, Shore displacement

\begin{abstract}
:
Glacial isostatic adjustment (GIA) is an ongoing phenomenon that characterizes the landscape of the High Coast $\left(63^{\circ} 04^{\prime} \mathrm{N}, 18^{\circ} 22^{\prime} \mathrm{E}\right.$, Sweden) / Kvarken archipelago $\left(63^{\circ} 16^{\prime} \mathrm{N}, 21^{\circ} 10^{\prime} \mathrm{E}\right.$, Finland) UNESCO World Heritage site. GIA occurs as the Earth's crust that was depressed by the continental ice sheet during the last glacial period is slowly rebounding towards isostatic equilibrium. The maximum rate of land uplift in the area is more than eight millimetres per year, which - along with the very different topographical reliefs of the opposite coasts - makes the region an excellent study area for land uplift as a phenomenon. As there is a marine area between the coasts, shore displacement is an essential part of the phenomenon in the study area.
\end{abstract}

The cartographic representation of GIA and shore displacement has classically relied on static maps representing isobases of the uplift rates and of ancient shorelines. However, to dynamically visualize and communicate the continuity and the nature of the phenomena, an animated map is required. To create a visually balanced, seamless animation, we need to create high-resolution image frames that represent digital elevation models (DEMs) together with extracted shorelines of different moments of time. To create these frames, we developed a mathematical model to transform the DEM in a given time for the past $\sim 9300$ years. We used the most recent LiDAR-derived DEMs of Finland and Sweden, and a bathymetric model of the Gulf of Bothnia as our initial data, along with a land uplift rate surface derived from geophysical measurements. We compared the current uplift rates with the shoreline observations of the ancient Baltic Sea stages, Litorina Sea and Ancylus Lake, and created a linear model between the elevations of the shorelines and the present-day uplift rates, as there was a near-linear correlation in both cases. Based on the current uplift rates and the elevations and the dating of the ancient shorelines, we derived an exponential model to describe the non-linear correlation between the elapsed time and the occurred land uplift. Near the present time, we adapted the formula proposed by Ekman (2001) to make the model more robust closer to the present day.

We assumed that although the uplift rate varies in time, the spatial relation of uplift rates remains the same. Furthermore, as the land uplift is an exponentially decelerating phenomenon occurring with a significantly lower annual rate than shortly after the de-glaciation (Eronen et al. 2001, Nordman et al. 2015), and with most of the total uplift already having occurred (Ekman 1991), we assumed a constant rate of uplift from the present day to the near geological future. We did not consider potential sea level changes caused by human-driven climate change in the predictions, as the geological time scale vastly exceeds the time range of the climate models. Neither did we take into account the historical transgression phases, as they did not appear dominating in the area.

The elevation and bathymetry data were harmonized and resampled into 4K (3840 x 2160) pixel dimensions to utilize the best commercially available screen resolutions and to avoid unnecessary sub-pixel level computations. This resulted in a spatial pixel size of about 200 metres. The initial spatial resolution of the DEMs of Finland and Sweden was 2 metres and 1 metre, respectively, while the bathymetric data had a spatial pixel size of 400 metres. This, along with the fact that the bathymetric data was partly modelled and inaccurate near the coastlines, meant that it had to be oversampled to generate plausible coastal bathymetry and to allow any future estimations of shore displacement. All the datasets were resampled to EPSG:3857 Pseudo-Mercator projection to facilitate any future use in web map applications. As the visualized area is only about 430 kilometres in the north-south direction, the use of this projection did not introduce cartographic issues.

The rendered frames required by the animation were produced with a programmatic conversion of raster files to RGBimages. The visualization of shore displacement was implemented by a discontinuity in elevation dependent colour scale at sea level. The bathymetry was visualized with a continuous colour scale in shades of blue until the elevation of zero metres. Elevations above zero were visualized with a colour scale starting from green to create an impression of a discrete shoreline (Figure 1). 


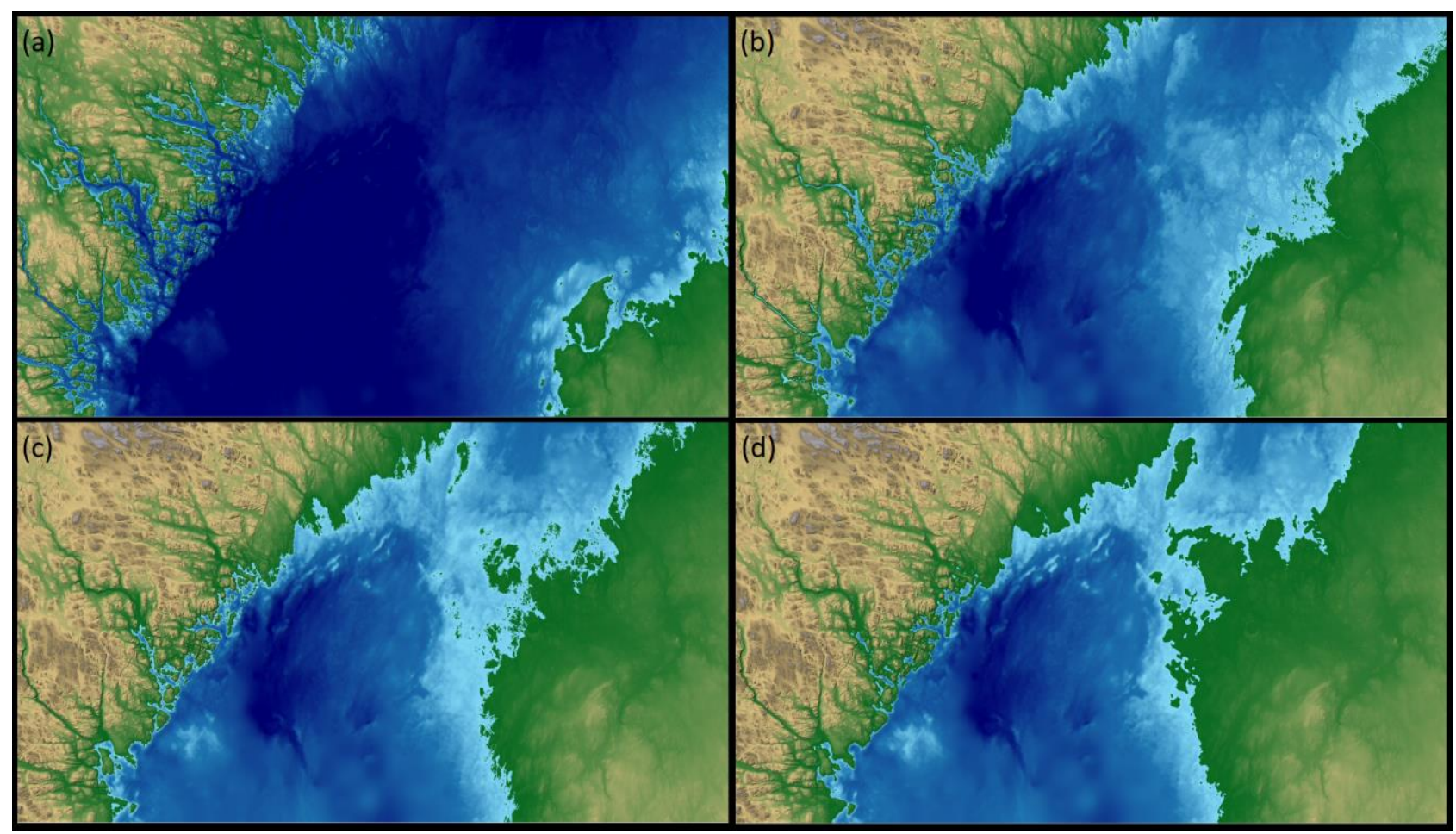

Figure 1. Examples of individual frames for the land uplift animation. Litorina stage 7300 BP (a), 3000 BP (b), current stage (c), and 1000 years after present (d). The imprecision of the predicted shoreline placement compared to the past reconstructions can be observed in the last frame.

The whole process from computing the DEMs to rendering the frames was implemented in Python, without the need for traditional GUI operated GIS or image processing software. The raster data was read and processed with GDAL and NumPy libraries, and the visualization was carried out using Matplotlib and Python Imaging Library. Each DEM was given the same elevation based colour scale and an individually created hillshading that was blended with the image by multiplication. The whole process was carried out as an open source solution.

The interval between the calculated frames was set to five years as, particularly at the Swedish coast, the shore displacement can appear abrupt with a longer time interval. The frame duration was set to 0.05 seconds, which means a 100 -second duration for an animation of 10000 years.

The resulting DEM reconstructions show good agreement with comparable data, such as the Litorina reconstructions by the Geological Survey of Finland (GTK). Also, the mathematical model appears to be in line with previous reconstructions conducted in the area (e.g. Nordman et al. 2015). So far, any continuous series of paleogeographic DEM reconstructions comparable to ours has not been published for this area. The animation provides an understandable way of perceiving the continuous but decelerating nature of the land uplift phenomenon and also highlights the differences in the post-glacial history of Finnish and Swedish coasts. To further improve the visualization, we must consider the removal of post-glacially developed features in the present day DEM, e.g. the various rivers that can both cause bias in the shore displacement and uplift estimations and appear visually distractive. In the very early frames of the animation, the retracting ice sheet must also be present. Also, a balanced addition of other cartographic elements, such as present-day hydrography and place names, can further improve the overall presentation. 